\title{
Design and Construction of a Low-Cost Device for the Evaluation of Redox Behaviour using Lineal Voltammetry Techniques
}

\author{
Kevin Rodriguez-Villarreal ${ }^{1}$, Alicia Alva ${ }^{2}$, Daniel Ramos-Sono ${ }^{3}$, Michael Cieza Terrones ${ }^{4}$, Avid Roman-Gonzalez ${ }^{5}$ \\ Image Processing Research Laboratory (INTI-Lab), Universidad de Ciencias y Humanidades, Lima, Perú ${ }^{1,2,3,5}$ \\ Servicio de Nefrología, Hospital Cayetano Heredia, Lima, Perú ${ }^{4}$
}

\begin{abstract}
Electrochemical techniques have been generating great interest due to their wide range of applications and their ease of use. For this reason, in recent years' electrochemical techniques such as cyclic voltammetry, anodic voltametric stripping, chronoamperometry and linear voltammetry have been developed. Linear voltammetry is one of the most widely used electrochemical techniques, where a voltage range is applied to a solution with the analyte and then current data is collected as a response. For this, an electrochemical cell with its 3 electrodes (working electrode, counter electrode, reference electrode) and a device for voltage control and current evaluation (potentiostat) is used. A potentiostat is an electronic device that allows the voltage or current to be regulated according to the electrochemical technique to be performed. The devices are usually very expensive due to their high precision, for this reason, our project is focused on the development of a low cost system that allows us to recognize redox systems by using linear voltammetry. our potentiostat system was able to differentiate in a redox salt (sodium chloride) from the support electrolytes (chlorohydric acid, nitric acid, sulfuric acid), allowing us to evaluate redox behavior at a cost of less than $\$ \mathbf{4 0}$.
\end{abstract}

Keywords-Potentiostat; blood lead; toxicity

\section{INTRODUCTION}

In last years, the electrochemical techniques have had a lot growing due to the increase of electronic precision, furthermore, the electrochemical techniques have taken on great importance due to widely range to applications. One of the most used electrochemical techniques is linear voltammetry, where applies an established voltage range and evaluates generated current. To perform lineal voltammetry, we use an electronic device called a potentiostat.

A potentiostat allows us to analyze and monitor redox mechanisms resulting from chemical reactions [1]. These chemical reactions are generated from the application of a range of voltages that is carefully controlled by the potentiostat to obtain current data. The current obtained can be related to the concentration of the chemical species involved, so the potentiostat is routinely used in analytical chemistry laboratories [2].

A potentiostat allows us to analyze and monitor redox mechanisms resulting from chemical reactions [1]. These chemical reactions are generated from the application of a range of voltages that is carefully controlled by the potentiostat to obtain current data. The current obtained can be related to the concentration of the chemical species involved, so the potentiostat is routinely used in analytical chemistry laboratories [2].

In the other hand, the accuracy of these devices has generated a growing interest in the use of these devices to other areas such as environmental monitoring, food safety, health, pharmacy, etc.

However, a high precision and quality potentiostat can to cost more than $\$ 10,000$ and prevent the popularization of these methodologies in low-cost laboratories resources in developing countries [3]. For this reason, a number of researches are being carried out to develop low-cost potentiometers for a wide range of applications, from the implementation of portable devices for the diagnosis or recognition of pathogens of importance in public health and food safety to the development of miniaturized high precision systems for metal traceability [4][11].

The present work was directed to the construction of a low cost potentiostat system that allows to perform linear voltammetry for diverse applications. Tests were carried out with three different electrolytes (nitric acid, sulphuric acid and hydrochloric acid) and redox species (potassium chloride, sodium chloride and potassium ferrocyanide) to observe the behavior of the circuit, with which results were obtained that were compared with a commercial potentiostat system (PalmSens), we analyzed and compared the characterization curves that allowed us to demonstrate that the circuit allows us to recognize the electrochemical behavior of redox species in electrolyte solutions, being useful for the respective analysis.

\section{MATERIALS AND MethodS}

\section{A. Design and Programming}

For the design of the electronic circuit, the software KiCad was used, in which the schematic (Fig. 1) proposed for the development of the equipment in mention was made. You can see all the components used, connection pins and description of some of the stages developed for the proper functioning.

The schematic includes a control stage, a visual indicators stage, voltage divider stage and mainly the measurement stage with the main component Arduino Nano that is in charge of controlling all the peripherals and data acquisition. 


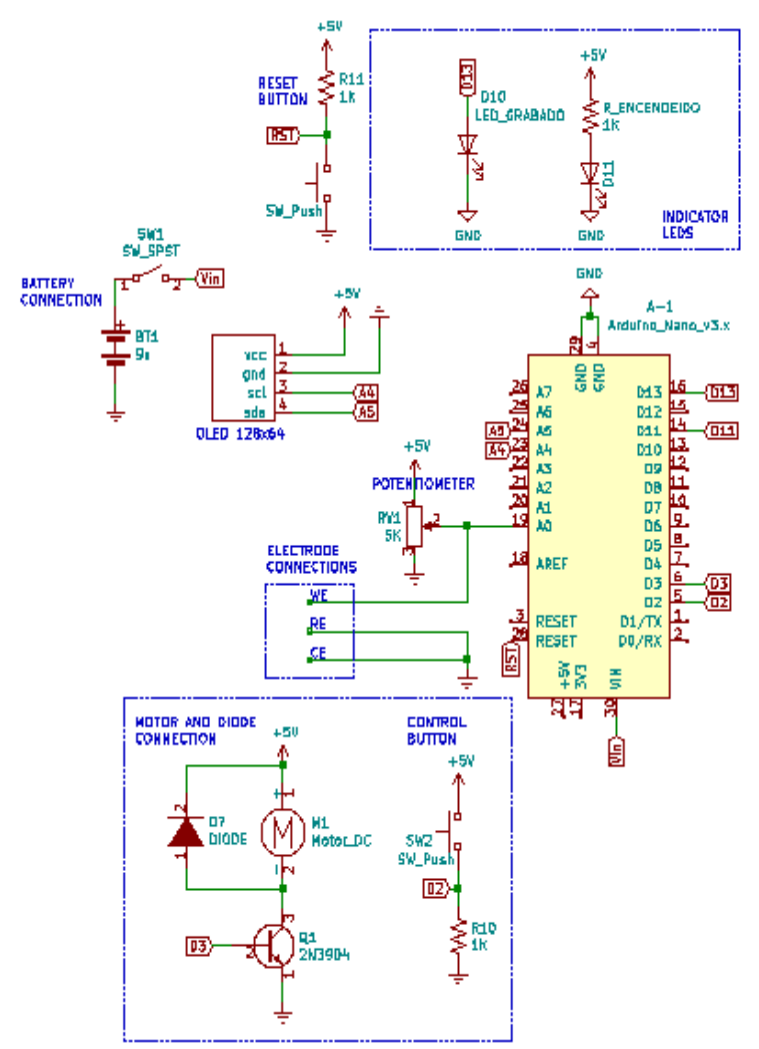

Fig. 1. Circuit Diagram of the Proposed System.

The proposed design was based on an Arduino Nano card, chosen as the main component due to its characteristics, which are sufficient for the operation of the circuit. In addition, the internal ATMEGA 328p microcontroller was used as the main element of the design (Fig. 2). This development board was used as an I2C communication interface to the 0.96" Oled screen for voltage and time data display.

A multiturn potentiometer in voltage divider configuration connected directly to the working electrode of the electrochemical cell was used for controlled regulation between the input voltage and the electrodes. This potentiometer was driven by a 6 -volt motor with a maximum speed of $1500 \mathrm{rpm}$. This motor assists in the automatic control of the voltage sweep speed.

Fig. 3 shows the connection between the multiturn potentiometer and the gear motor, they are connected between both shafts and this is operated by a normally open button (NO) that turns the motor clockwise. The potentiometer used as shown in Fig. 3 is $5 \mathrm{kohm}$ and the gear motor operates at $5 \mathrm{v}$ (volts). Finally, a 9v battery was used for system portability.

For the data acquisition stage, the Arduino's analog port (A0) was used to collect time values (ms) since the equipment is connected and voltage values (v) since the motor turns and performs the sweep. Both results are stored and exported in a CSV file. Once you have this file with the corresponding data, this information is imported into Matlab to be able to perform a characterization of the results and observe the behavior of the redox process in the equipment. Finally, a $9 \mathrm{v}$ battery was used for system portability.

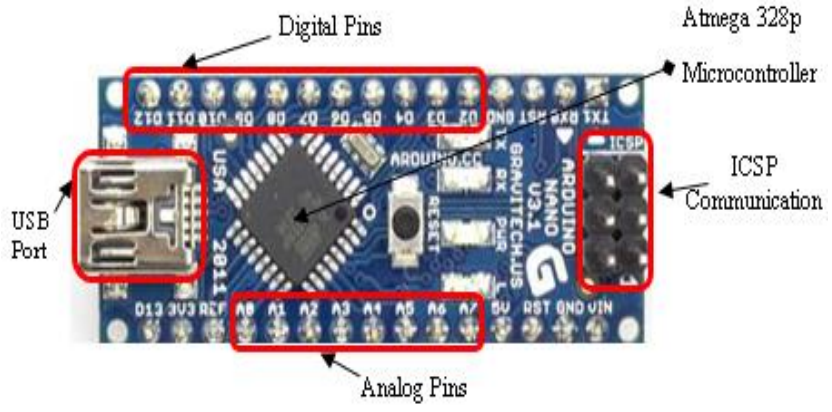

Fig. 2. Description of the Pins of the Arduino Nano Board.

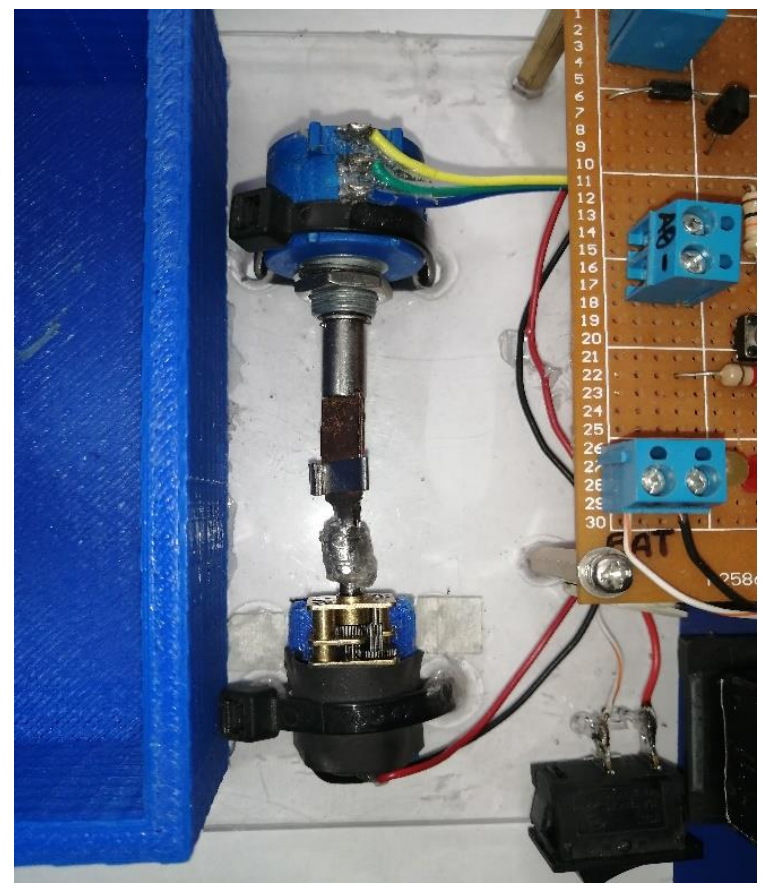

Fig. 3. "a" and "b" are Linear Multi-Turn Potenciometers "c" is the Connection of the DC Reducer Motor to the Axis of the Multiturn Potentiometer.

The following flow chart shows the operating stages of the control algorithm created for data collection in the Fig. 4.

\section{B. Electrochemical Cell}

For some previous tests, a charge representing an electrochemical solution was required, which is why he made a test plate similar to a dummy cell for these tests. The test plate is seen in Fig. 5.

The response behavior of voltage generated by voltage divider without an electrochemical cell was evaluated.

To do this, the analog A0 input of the Arduino card was connected to an oscilloscope probe on channel $2(\mathrm{CH} 2)$, the DC motor was scanned without connecting any test load, and the waveform was observed. In addition, the wave behavior was evaluated when the system was connected to an equivalent circuit.

Fig. 5 shows a test plate implemented in the laboratory, which was built with electronic components, such as: 
- Resistors from $10 \mathrm{k} \Omega, 560 \Omega, 560 \Omega, 10 \mathrm{k} \Omega$

- Semiconductor diodes $1 \mathrm{n} 4001$

- $10 \mathrm{nf}$ ceramic capacitors

\section{Evaluation of Electrochemical behavior}

Before the electrochemical evaluation, the electrodes were carefully washed with a pyranha solution (1 hydrogen peroxide: 1 ammonium hydroxide: 5 milliQ water) where the counter electrode (platinum) was immersed for a maximum period of 10 seconds, followed by a thorough MiliQ water wash. This procedure was repeated 5 times.

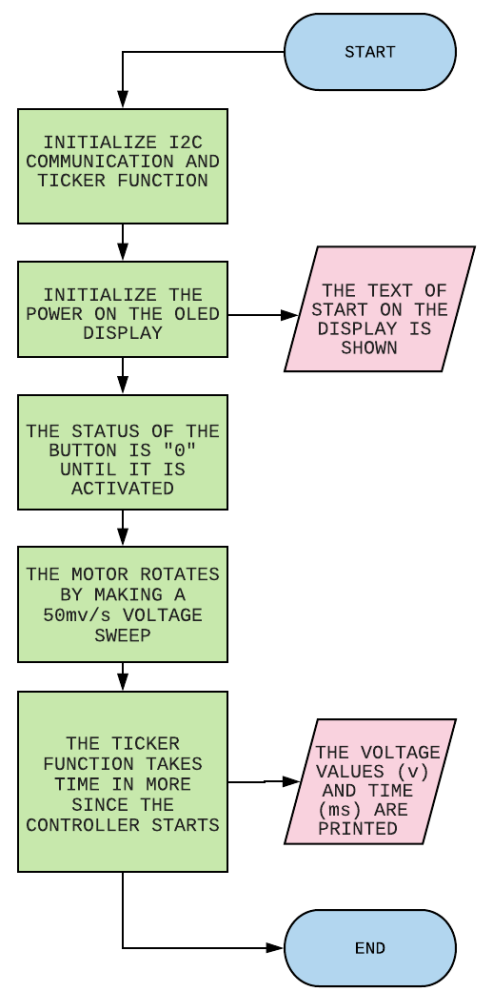

Fig. 4. Flow Chart of the States of the Measurement Process by the Equipment.

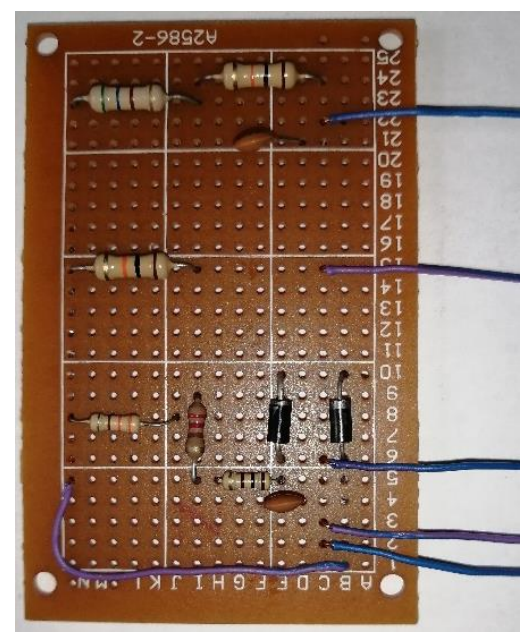

Fig. 5. Homemade Dummy Cell to Emulate an Electrochemical Cell and use it as a Charge.
On the other hand, the working electrode (carbon) was placed for 5 minutes in pyranha solution, followed by abundant MiliQ water washings, this procedure was repeated 5 times. For the electrochemical measurements, an electrochemical cell with a configuration of two electrodes was used; a working electrode and a counter electrode.

Three different support electrolytes were used; hydrochloric acid, sulphuric acid, nitric acid and a potassium chloride salt at a concentration of $0.1 \mathrm{M}$ in MiliQ water. In addition, we evaluated the selectivity of the system to recognize a salt (potassium chloride) in a nitric acid solution. The measurements were made on an electrochemical cell with a two-electrode configuration; a platinum electrode as counter electrode and a carbon electrode as working electrode. A potential window of 0 to 2.7 volts was applied. The AD HOC potentiostat system collected 9 random voltage points.

\section{Comparative Analysis with Other Potentiostats}

In this section, the main characteristics and indications of the proposed low-cost potentiostat are mentioned compared to other potentiostats with higher performance and greater precision (Table I).

Table I shows a comparison of the proposed equipment with four other equipment with similar benefits [12].

TABLE I. EQUIPMENT COMPARISION

\begin{tabular}{|c|c|c|c|c|c|}
\hline & $\begin{array}{l}\text { Potentiostat } \\
\text { Ad Hoc (In } \\
\text { this Work) }\end{array}$ & UMED 1 & $\begin{array}{l}\text { Cheap } \\
\text { Stat }\end{array}$ & Dstat & $\begin{array}{l}\text { potentiost } \\
\text { at / } \\
\text { galvanost } \\
\text { at }\end{array}$ \\
\hline $\begin{array}{l}\text { Open } \\
\text { source }\end{array}$ & Yes & No & Yes & Yes & Yes \\
\hline $\begin{array}{l}\text { Power } \\
\text { source }\end{array}$ & $\begin{array}{l}\text { Rechargeab } \\
\text { le battery }\end{array}$ & $\begin{array}{l}\text { Rechargeab } \\
\text { le battery }\end{array}$ & $\begin{array}{l}\text { 2xAA } \\
\text { Batteries } \\
\text { or Usb } \\
\text { conectio } \\
\text { n }\end{array}$ & $\begin{array}{l}\text { Usb } \\
\text { conectio } \\
\text { n }\end{array}$ & $\begin{array}{l}\text { Usb } \\
\text { conection }\end{array}$ \\
\hline $\begin{array}{l}\text { Hardwa } \\
\text { re } \\
\text { interfac } \\
\text { es }\end{array}$ & $\begin{array}{l}\text { Oled } 0.96 " \\
128 \times 64 \text { and } \\
\text { one control } \\
\text { button }\end{array}$ & $\begin{array}{l}\text { Led display } \\
\text { and three } \\
\text { buttons }\end{array}$ & $\begin{array}{l}\text { Lcd } \\
\text { display } \\
\text { and } \\
\text { joystick }\end{array}$ & $\begin{array}{l}\text { Doesn't } \\
\text { have }\end{array}$ & $\begin{array}{l}\text { Doesn't } \\
\text { have }\end{array}$ \\
\hline $\begin{array}{l}\text { Voltage } \\
\text { range }\end{array}$ & $\begin{array}{l}0 \text { to } 2.5 \mathrm{v} \\
\text { (50mV } \\
\text { resolution) }\end{array}$ & $\begin{array}{l}-2 \mathrm{v} \text { to }+2 \mathrm{v} \\
(50 \mathrm{uV} \\
\text { resolution) }\end{array}$ & $\begin{array}{l}-1 \mathrm{v} \text { to } \\
+1 \mathrm{v} \\
\text { resolutio } \\
\mathrm{n}\end{array}$ & $\begin{array}{l}-1.5 \mathrm{v} \text { to } \\
+1.5 \mathrm{v} \\
(46 \mathrm{uV} \\
\text { resolutio } \\
\mathrm{n})\end{array}$ & $\begin{array}{l}8 \mathrm{v} \\
(15.3 \mathrm{uV} \\
\text { resolution } \\
)\end{array}$ \\
\hline $\begin{array}{l}\text { Current } \\
\text { range }\end{array}$ & 0 to $15 \mathrm{uA}$ & $\begin{array}{l}-200 \mathrm{uA} \text { to } \\
+200 \mathrm{uA}\end{array}$ & $\begin{array}{l}-10 \mathrm{uA} \text { to } \\
+10 \mathrm{uA}\end{array}$ & $\begin{array}{l}\text { limit of } \\
\text { detection } \\
600 f A\end{array}$ & $\begin{array}{l}-20 \mathrm{~mA} \text { to } \\
+20 \mathrm{~mA}\end{array}$ \\
\hline
\end{tabular}

\section{RESULTS}

This section shows some of the results obtained with the low-cost potentiostat and a higher-performance potentiostat.

\section{A. Signal Verification}

For the analysis and understanding of the behavior of the proposed electronic circuit, 2 calibration tests were performed in order to verify the operation of the equipment and the reading of the data. 
For the first experience, as shown in Fig. 6. A measurement probe was connected to the Arduino's A0 analog port where the voltage vs. time data is entered. The probe goes to channel 2 $(\mathrm{CH} 2)$ of the oscilloscope and we can see that the signal has noise when it is read with a peak-to-peak voltage ( $\mathrm{Vpp}$ ) of $2.5 \mathrm{v}$.

In this experience the data obtained was exported in a CSV file and then the response curve was made, obtaining the following.

The graph obtained in Fig. 7 shows a discontinuous calibration curve. The no-load voltage sweep (dummy cell) was performed, obtaining the aforementioned curve.

For the second experience, as shown in Fig. 8. The same probe was connected to the analog $\mathrm{A} 0$ port of the Arduino where the voltage vs. time data are entered, with the difference that this time a load (Dummy cell) was connected to the A0 input and to the probe, observing that the signal does not have as much noise as the previous one and is controlled by the cell representing an electrochemical cell. For this second experience the data obtained were exported in a CSV file to make the respective graph.

The graph obtained in Fig. 9 shows a continuous and unaltered calibration curve. The voltage sweep with load (Dummy cell) was performed obtaining the aforementioned curve.

It is observed from the two tests carried out that the representation of an electrochemical cell by means of a Dummy cell helps to neutralize external factors such as noise and to be able to maintain a stable and unaltered calibration curve. In both tests, the voltage vs. time axes were taken to make the respective graphs and to be able to compare them.

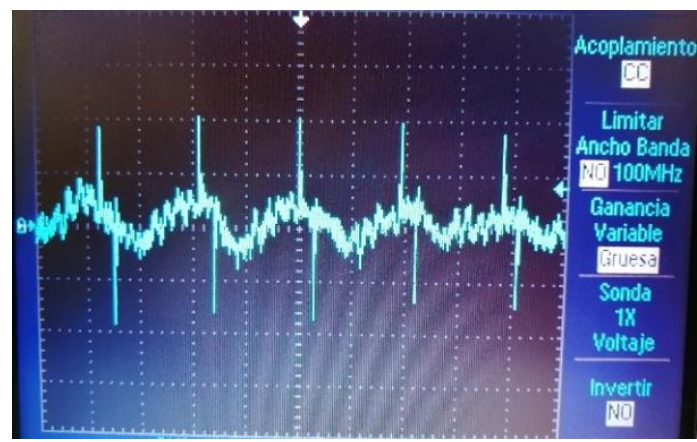

Fig. 6. Read Response at analog Input A0 Measuring without a Dummy Cell.

Calibration curve without Dummy Cell

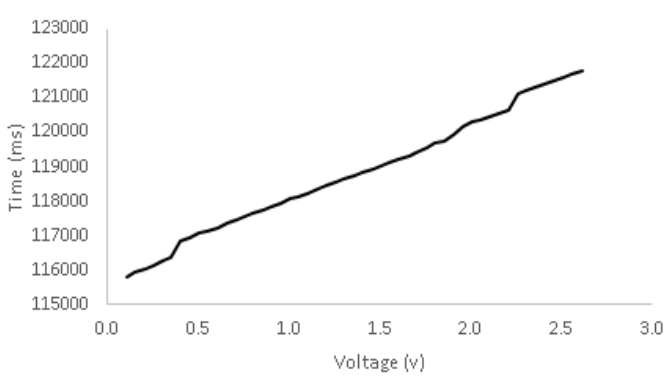

Fig. 7. Circuit Diagram of the Proposed System.

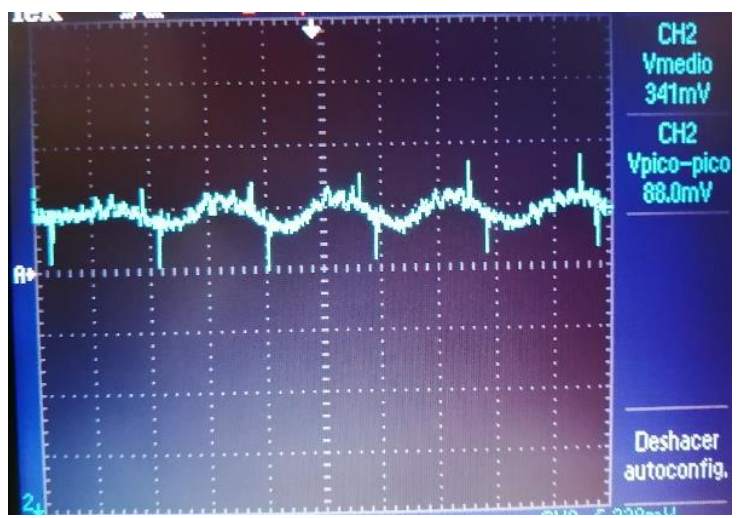

Fig. 8. Read Response at the analog A0 Input Measuring with a Homemade Dummy Cell.

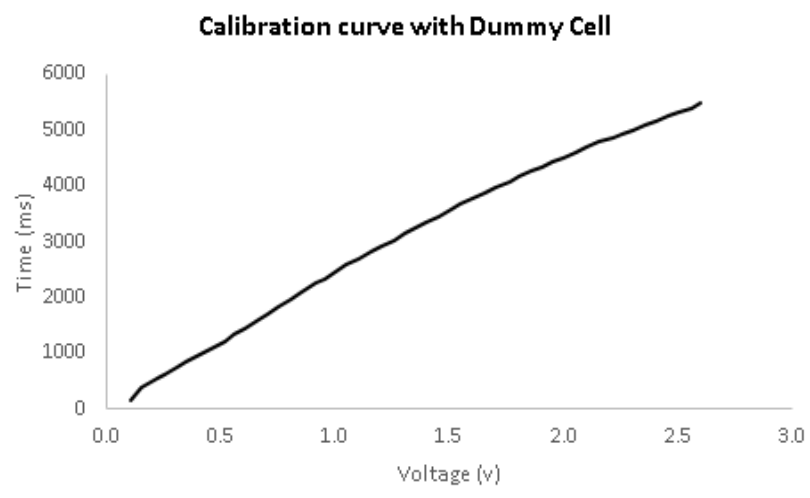

Fig. 9. Circuit Diagram of the Proposed System.

\section{B. Response Device}

The built in AD HOC potentiostat allowed us to obtain the time it takes to go from one voltage point to another. The time value that was obtained was assumed to be a current value produced by the electrochemical system, however, it will be necessary to contrast the data with a standard potentiostat system.

Some results obtained in the laboratory of the electrochemical processes carried out are shown in the following figure.
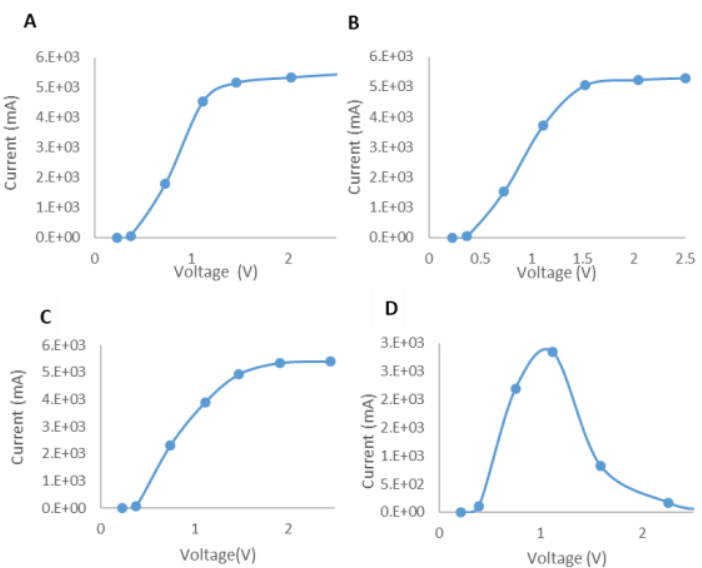

Fig. 10. A. Chlorhydric Acid 0.1M. B. Sulfuric Acid 0.1M, C. Nitric Acid. D. Potassium Chloride $0.1 \mathrm{M}$. 
On the other hand, Fig. 10 Letter (A, B and C) shows the response of the potentiostat when applying a potential range on support electrolytes, where the hydrochloric acid and sulphuric acid show a linear trend up to a voltage of 1.5 voltsconstant, this is a product of the over-potential, in the case of nitric acid, shows us almost linear trend, without the presence of on-set in the range of applied voltage. This can be explained as the saturation of dissolved ions given by the total dissociation of strong acids in solution which is closely related to the Ionic strength, nitric acid presents a lower ionic strength than the two acids mentioned above.

In the case of the potassium chloride, a peak in the 1.13 volts is observed, according to the literature it mentions that the Chlorine in an aqueous solution presents an oxidation process in 1.23 volts.

\section{CONCLUSIONS}

The results show that our low cost device allows to identify in a very close way current peaks related to oxidation of some element, this system is relatively simple and very cheap, being a device that works very well as a proof of concept, being very easy to replicate and simple to use for places where it does not have chemical analysis tools. Therefore, we believe that it is an interesting tool that could help the development of rapid methods for the detection of redox elements from their oxidation peak.

\section{FUTURE WORK}

This electronic measuring circuit for redox processes, will serve us to be able to make modifications later on and not only detect oxidetion processes but also different electrochemical tecniques of reduction and oxidation systema for the characterization of several laboratory solutions

\section{ACKNOWLEDGMENT}

We want to thank the Image Processing Research Laboratory (INTI-Lab) and the Universidad de Ciencias y Humanidades $(\mathrm{UCH})$ for their support in this research, the
National Fund for Scientific, Technological and Technological Innovation (FONDECYT), according to the contract " $\mathrm{N}^{\circ} 091$ 2018-FONDECYT-BM-IADT-AV "for the financing of this project and the Electronics Laboratory of the $\mathrm{UCH}$ for assigning us their facilities and being able to carry out the respective tests.

\section{REFERENCES}

[1] K. Kellner, T. Posnicek, J. Ettenauer, K. Zuser, and M. Brandl, “A new , low-cost potentiostat for environmental measurements with an easy-touse PC interface," Procedia Eng., vol. 120, no. 0, pp. 956-960, 2015.

[2] M. D. Steinberg and C. R. Lowe, "A micropower amperometric potentiostat," vol. 97, no. July 2003, pp. 284-289, 2004.

[3] A. A. Rowe, A. J. Bonham, R. J. White, M. P. Zimmer, R. J. Yadgar, M. Tony, J. W. Honea, I. Ben-yaacov, and K. W. Plaxco, "Potentiostat for Analytical and Educational Applications," vol. 6, no. 9, 2011.

[4] M. D. M. Dryden and A. R. Wheeler, "DStat: A Versatile , OpenSource Potentiostat for Electroanalysis and Integration," pp. 1-17, 2015.

[5] C. Huang, M. Syu, and Y. Chang, "A portable potentiostat for the bilirubin-specific sensor prepared from molecular imprinting," vol. 22, pp. 1694-1699, 2007.

[6] P. Pittet, G. Lu, J. Galvan, R. Ferrigno, L. J. Blum, B. D. Leca-bouvier, and I. T. Cmos, "PCB Technology-Based Electrochemiluminescence Analytical Systems," vol. 8, no. 5, pp. 565-571, 2008.

[7] C. Yang, Y. Huang, S. Member, B. L. Hassler, R. M. Worden, A. J. Mason, and S. Member, "Amperometric Electrochemical Microsystem for a Miniaturized Protein Biosensor Array," vol. 3, no. 3, pp. 160-168, 2009.

[8] A. Carullo, F. Ferraris, M. Parvis, A. Vallan, E. Angelini, and P. Spinelli, "Low-Cost Electrochemical Impedance Spectroscopy System for Corrosion Monitoring of Metallic Antiquities and Works of Art," vol. 49, no. 2, pp. 371-375, 2000.

[9] A. Felipe, D. Cruz, N. Norena, A. Kaushik, and S. Bhansali, "Biosensors and Bioelectronics A low-cost miniaturized potentiostat for point-ofcare diagnosis," Biosens. Bioelectron., vol. 62, pp. 249-254, 2014.

[10] T. Arévalo-ramírez, C. C. Torres, C. Rosero, and P. Espinoza-montero, "for its design and construction," 2016.

[11] T. Arévalo-ramírez, C. C. Torres, C. Rosero, and P. Espinoza-montero, "for its design and construction," 2016.

[12] A. Ainla et al., "Open-Source Potentiostat for Wireless Electrochemical Detection with Smartphones," Anal. Chem., vol. 90, no. 10, pp. 62406246, May 2018. 